\title{
STRUSKY PO TAVBĚ POLYMETALICKÝCH RUD Z LOKALITY ČEJKOV-TRSOV (PELHŘIMOVSKÝ RUDNÍ REVÍR)
}

\author{
Slags after smelting of polymetallic ores from the locality Čejkov-Trsov (Pelhřimov Ore District) \\ Jaroslav Kapusta ${ }^{1,2}$, Zdeněk Dolníček ${ }^{1}$, Karel Malýs \\ ${ }^{1}$ Katedra geologie PřF UP, 17. listopadu 1192/12, 77146 Olomouc; e-mail: jaroslav.kapusta@gmail.com \\ 2 Ústav geologických věd PřF MU, Kotlářská 2, 61137 Brno \\ ${ }^{3}$ Muzeum Vysočiny Jihlava, Masarykovo nám. 55, 58601 Jihlava
}

(23-23 Jihlava)

Key words: Pelhřimov Ore District, polymetallic ores, slags, heavy metals

\begin{abstract}
Slags after smelting of polymetallic ores occur at the locality Čejkov-Trsov which represents medieval smelting site and lies approximately $1030 \mathrm{~m}$ SE from the center of the Čejkov village. Samples collected during archaeological excavation were obtained from the Museum Vysočiny Jihlava. Bulk chemical analyses show that studied slags are dominated by $\mathrm{SiO}_{2}-\mathrm{FeO}-\mathrm{Al}_{2} \mathrm{O}_{3}$ oxides (sum of these three components is 75.27-88.81 wt. \%). Unusual are high barium (up to $9.2 \mathrm{wt}$. \% of Ba) and lead contents (up to $15.0 \mathrm{wt}$. \% of Pb) as well as low zinc contents (230-3780 ppm). All samples except one are generally CaO poor (an exception is sample CT4 containing 6.03 wt. \% CaO) which probably reflect lack of $\mathrm{CaO}$ - based additives. Light microscopy and EDS analyses on an electron microprobe proved following phases: spinelides, olivine, feldspars, pyroxene, glass and quartz. Spinelides are the most variable in their composition ranging from almost pure magnetite ( $92 \mathrm{~mol}$. \% of magnetite, $5 \mathrm{~mol}$. \% of spinel and $3 \mathrm{~mol}$. \% of galaxite) to spinel-rich hercynite (50 mol. \% of hercynite, $45 \mathrm{~mol}$. \% of spinel and $5 \mathrm{~mol}$. \% of magnetite). Olivine is represented by fayalite (89-90 mol. \% $\mathrm{Fa}, 5-7 \mathrm{~mol} . \% \mathrm{Te}, 4-5 \mathrm{~mol}$. \% Fo). Newly formed feldspars are present in all studied samples and contain up to $22.8 \mathrm{wt}$. \% of BaO (44-50 mol. \% of orthoclase, 40-47 mol. \% of celsiane and 9-11 mol. \% of albite). Ca-Fe pyroxene $\left(F s_{52} W_{38} E n_{11}-F s_{51} W o_{37} E n_{13}\right)$ was formed probably due to high enough temperature and a sufficient $\mathrm{CaO}$ content. Cracked quartz grains are present within all samples. They were more or less corroded by a slag melt.
\end{abstract}

Úvod

Pelhřimovský rudní revír, o celkové rozloze cca 200 km², zaujímá prostor mezi Horní Cerekví, Humpolcem, Pelhřimovem a Herálcem. Po stránce regionálně geologické spadá do moldanubické oblasti při západním kontaktu východní větve centrálního moldanubického plutonu s metamorfity moldanubika Šumavy a jižních Čech (Litochleb 2001).

$\mathrm{V}$ menším měřítku zde bylo historicky těženo Au-zrudnění stratiformního typu (Litochleb 1981). Intenzivněji bylo $\mathrm{v}$ revíru exploatováno spodnopermské žilné $\mathrm{Fe}-\mathrm{Zn}-\mathrm{Pb}-\mathrm{Ag}(\mathrm{Cu})$ zrudnění typu k-pol (Bernard 1991). Typická je pro ně žilovina tvořená téměř výhradně křemenem, ke kterému jen velmi vzácně přistupují karbonáty (siderit, ankerit a kalcit). Z rudních minerálů převažuje pyrit, arzenopyrit a tmavý, černohnědý sfalerit. Mezi běžné patří i galenit (Litochleb 2001). Spíše ojedinělý je pak tetraedrit (Litochleb - Pavlíček 1981), stejně jako chalkopyrit a akantit (Litochleb 2001).

Těžba $\mathrm{v}$ pelhřimovském rudním revíru probíhala $\mathrm{v}$ několika časových epochách. Za nejúspěšnější se dají označit její počátky v 13. stol. S postupným odtěžením perspektivních cementačních zón a zvyšováním technologické náročnosti těžby docházelo $\mathrm{k}$ jejímu postupnému úpadku, který vyvrcholil s příchodem husitských válek v 15. stol. Další etapa hornictví (v 16. stol.) byla spojena s pokusy o obnovu těžby a to převážně ze strany drobných podnikatelů. 18. a 20. stol. představuje spíše práce zaměřené na rekognoskaci starých důlních děl (Litochleb 1996).
Cílem tohoto příspěvku je zhodnocení struskových hmot z lokality Čejkov-Trsov z pohledu fázového složení a celkového chemismu a následné využití získaných dat pro posouzení podmínek tavby a složení vsázky.

\section{Metodika}

Vybrané vzorky byly upraveny do podoby leštěných nábrusů, které byly následně analyzovány metodou EDX na elektronové mikrosondě JXA 8600, instalované na katedře geologie Univerzity Palackého v Olomouci. Současně byly také pořízeny snímky ve zpětně odražených elektronech (BSE). Podmínky analýzy byly následující: proud svazku $10 \mathrm{nA}$, urychlovací napětí $15 \mathrm{kV}$, doba načítání pulzů $100 \mathrm{~s}$.

Celkový chemismus byl stanovován na práškových vzorcích v laboratořích ACME v Kanadě. Hlavní oxidy byly stanoveny metodou ICP-ES, stopové prvky metodou ICP-MS. Celkový uhlík a síra byly analyzovány na analyzátoru Leco.

\section{Výsledky}

Strusky byly pro potřeby studia poskytnuty ze sbírek jihlavského Muzea Vysočiny. Jejich sběr proběhl ve dvou etapách archeologického výzkumu, a to v letech 2011 a 2014. Pvrchovým sběrem bylo celkem získáno x kg struskových hmot. Sběr na lokalitě Čejkov-Trsov, hutniště u potoka (viz obr. 1) realizoval P. Hrubý z organizace Archaia Brno. Lokalita se nachází přibližně $2,5 \mathrm{~km}$ od zaniklého hutnického areálu Cvilínek, který leží přibližně $550 \mathrm{~m}$ sv. od středu obce Černov a jehož působnost je datována 


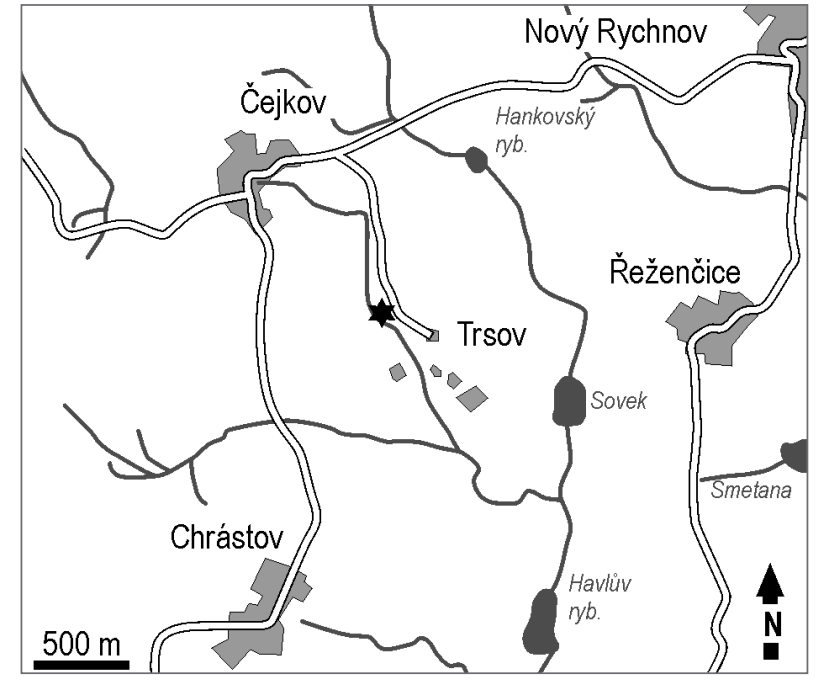

Obr. 1: Geografická pozice studované lokality. Hvězdička - odběrové místo.

Fig. 1: Geographic position of the studied locality. Asterisk - the sampling site.

do 13. stol (Hrubý et al. 2011). GPS souřadnice lokality jsou: $49^{\circ} 22^{\prime} 9,476^{\prime \prime} \mathrm{N}$ a $15^{\circ} 19^{\prime} 51,840^{\prime \prime} \mathrm{E}$.

Nalezeny byly pouze fragmenty strusek, které svou velikostí nepřesahují první desítku $\mathrm{cm}$. Přítomny jsou strusky zcela nepravidelného tvaru. Jejich povrch je matný s barvou od tmavě šedé po černou. Barva práškových vzorků je tmavě šedá, někdy s odstínem do zelené. Běžná je i prrítomnost okrově zbarvených povlaků oxy-hydroxidů železa na povrchu a v puklinách vzorkủ. V důsledku navětrání mají některé vzorky šedobíle zbarvený povrch. $\mathrm{Na}$ řezu jsou často patrná zrna křemene o velikosti do $1 \mathrm{~cm}$ a drobné (max. několik mm velké) inkluze sulfidů.

Chemismus studovaných vzorků je $\mathrm{v}$ podstatné míre zastoupen třemi komponentami: $\mathrm{SiO}_{2}-\mathrm{FeO}-\mathrm{Al}_{2} \mathrm{O}_{3}$ (suma uvedených oxidů 75,27-88,81 hm. \%) - tab. 1 . Mezi hlavními oxidy jsou nejméně variabilní obsahy $\mathrm{SiO}_{2}(41,56-50,24 \mathrm{hm} . \%), \mathrm{Al}_{2} \mathrm{O}_{3}(5,98-7,83 \mathrm{hm}$. \%), $\mathrm{FeO}$ (19,59-33,06 hm. \%), $\mathrm{Na}_{2} \mathrm{O}(0,36-0,48 \mathrm{hm} . \%)$ a $\mathrm{K}_{2} \mathrm{O}$ (2,01-2,98 hm. \%). Naopak nejvíce rozkolísané jsou obsahy $\mathrm{P}_{2} \mathrm{O}_{5}(0,28-1,66 \mathrm{hm} . \%)$ a $\mathrm{MnO}(0,29-2,15 \mathrm{hm}$. \%). Obsahy CaO jsou stabilní ve vzorcích CT1-CT3 $(2,34-2,42 \mathrm{hm}$. \%), odchylku představuje struska CT4 (s 6,03 hm. \% CaO). Mezi těžkými kovy jednoznačně dominuje $\mathrm{Pb}$ (1940$150000 \mathrm{ppm})$. V podstatně menši míře jsou zastoupeny Zn (230-3 780 ppm) a Cu (164-508 ppm). Vzorky CT2 a CT3 vykazují nejvyšší obsahy metaloidů (503-605 ppm As a 31-138 ppm Sb). Stříbro je př́tomno v obsazích 89,5-311,0 ppm. Vzorek CT4 je zajímavý vysokým obsahem $\mathrm{Ba}(9,2 \mathrm{hm} . \%)$, který je rovněž provázen zvýšeným obsahem Sr (2180 ppm).

Identifikovány byly následující fázové asociace:

F1 - živec, sklo

F2 - spinelid, živec, olivín, sklo

F3 - živec, pyroxen, olivín, sklo

Ve všech asociacích lze dále konstatovat prítomnost silně rozpraskaných a otavených izometrických zrn
Tab. 1: Celkový chemismus strusek (oxidy ve hm. \%, prvky v ppm s výjimkou Au v ppb). TOT/C - celkový uhlík, TOT/S - celková síra, LOI - ztráta žíháním.

Tab. 1: Bulk chemical composition of slags (oxides in wt. \%, elements in ppm except for $\mathrm{Au}$ in $\mathrm{ppb}$ ). TOT/C - total carbon, TOT/S - total sulphur, LOI - loss on ignition.

\begin{tabular}{|l|c|c|c|c|}
\hline Vzorek & CT1 & CT2 & CT3 & CT4 \\
\hline $\mathrm{P}_{2} \mathrm{O}_{5}$ & 1,66 & 0,59 & 0,64 & 0,28 \\
\hline $\mathrm{SiO}_{2}$ & 48,30 & 41,56 & 50,24 & 46,39 \\
\hline $\mathrm{TiO}_{2}$ & 0,20 & 0,46 & 0,42 & 0,35 \\
\hline $\mathrm{Al}_{2} \mathrm{O}_{3}$ & 7,45 & 7,83 & 6,78 & 5,98 \\
\hline $\mathrm{Cr}_{2} \mathrm{O}_{3}$ & 0,00 & 0,01 & 0,01 & 0,00 \\
\hline $\mathrm{CaO}$ & 2,42 & 2,35 & 2,34 & 6,03 \\
\hline $\mathrm{FeOtot}$ & 33,06 & 34,33 & 19,59 & 22,90 \\
\hline $\mathrm{MgO}$ & 0,49 & 0,65 & 0,80 & 1,29 \\
\hline $\mathrm{MnO}$ & 0,50 & 2,15 & 0,29 & 1,19 \\
\hline $\mathrm{K} \mathrm{K}_{2} \mathrm{O}$ & 2,98 & 2,98 & 2,34 & 2,01 \\
\hline $\mathrm{Na}{ }_{2} \mathrm{O}$ & 0,48 & 0,43 & 0,36 & 0,38 \\
\hline $\mathrm{TOT} / \mathrm{C}$ & 0,02 & 0,24 & 0,17 & 0,18 \\
\hline $\mathrm{TOT} / \mathrm{S}$ & 0,88 & 0,28 & 0,11 & 0,97 \\
\hline $\mathrm{LOI}$ & $-3,80$ & $-3,40$ & $-1,40$ & $-1,20$ \\
\hline $\mathrm{Suma}$ & 94,64 & 90,45 & 82,68 & 86,75 \\
\hline $\mathrm{Pb}$ & 24400 & 60200 & 150000 & 1940 \\
\hline $\mathrm{Zn}$ & 230 & 940 & 752 & 3780 \\
\hline $\mathrm{Ba}$ & 706 & 596 & 469 & 92000 \\
\hline $\mathrm{Cu}$ & 164 & 339 & 508 & 421 \\
\hline $\mathrm{Sr}$ & 133 & 169 & 166 & 2180 \\
\hline $\mathrm{As}$ & 107 & 605 & 503 & 134 \\
\hline $\mathrm{Ag}$ & 89,5 & 91,7 & 311 & 168 \\
\hline $\mathrm{Sb}$ & 8,00 & 31,3 & 138 & 27,6 \\
\hline $\mathrm{Au}$ & 22,8 & 16,1 & 21,2 & 85,0 \\
\hline
\end{tabular}

křemene a inkluzí sulfidů a oxidů olova. $\mathrm{V}$ proměnlivém množství je prrítomno sklo. U asociace F1 a F2 tvoří podstatnou část objemu struska. Asociace F3 obsahuje téměř výhradně nově vzniklé krystalické fáze, jen výjimečně byly pozorovány domény s významnějším zastoupením skla.

Pokud je př́tomen spinelid, krystalizuje z taveniny jako první. Přednostně tvoří izometrická zrna s vysokým stupněm automorfie. Nicméně, jak je patrné $\mathrm{z}$ obrázku 2a, jeho tvar může být i méně pravidelný, př́ípadně může vytvářet i složitější srostlice. Jeho velikost je proměnlivá a pohybuje se od jednotek po desítky $\mu \mathrm{m}$. Chemismus analyzovaných spinelidů je mezi jednotlivými vzorky značně proměnlivý (tab. 2). Ve strusce CT2 byl analyzovaný téměř čistý magnetit (92 mol. \%), jen s nepatrným zastoupením spinelového (5 mol. \%) a galaxitového (3 mol. \%) koncového členu. Naopak v př́ípadě vzorku CT3 (obr. 2b) se jedná o spinelovou komponentou bohatý hercynit (50 mol. \% hercynit, $45 \mathrm{~mol}$. \% spinel a $5 \mathrm{~mol}$. \% magnetit).

$\mathrm{Z}$ novotvořených fází byly pouze živce prítomny ve všech studovaných vzorcích. Jejich morfologie je značně proměnlivá i v rámci jednoho vzorku. Velikost živců kolísá od jednotek až po stovky $\mu \mathrm{m}$. Pozorovány byly izometrické, ale i lištovité průřrezy s vysokým stupněm automorfie. Obvyklé jsou i složitější srostlice. Chemismus je zajímavý zvýšenými obsahy $\mathrm{Ba}(a z ̌$ 22,8 hm. \% BaO u vzorku CT4). Vyjádřeno koncovými členy převažuje K-živec (44-50 mol. \%) a celsian (40-47 mol. \%), v menším množství je zastoupen i albit (9-11 mol. \%). Běžně je 

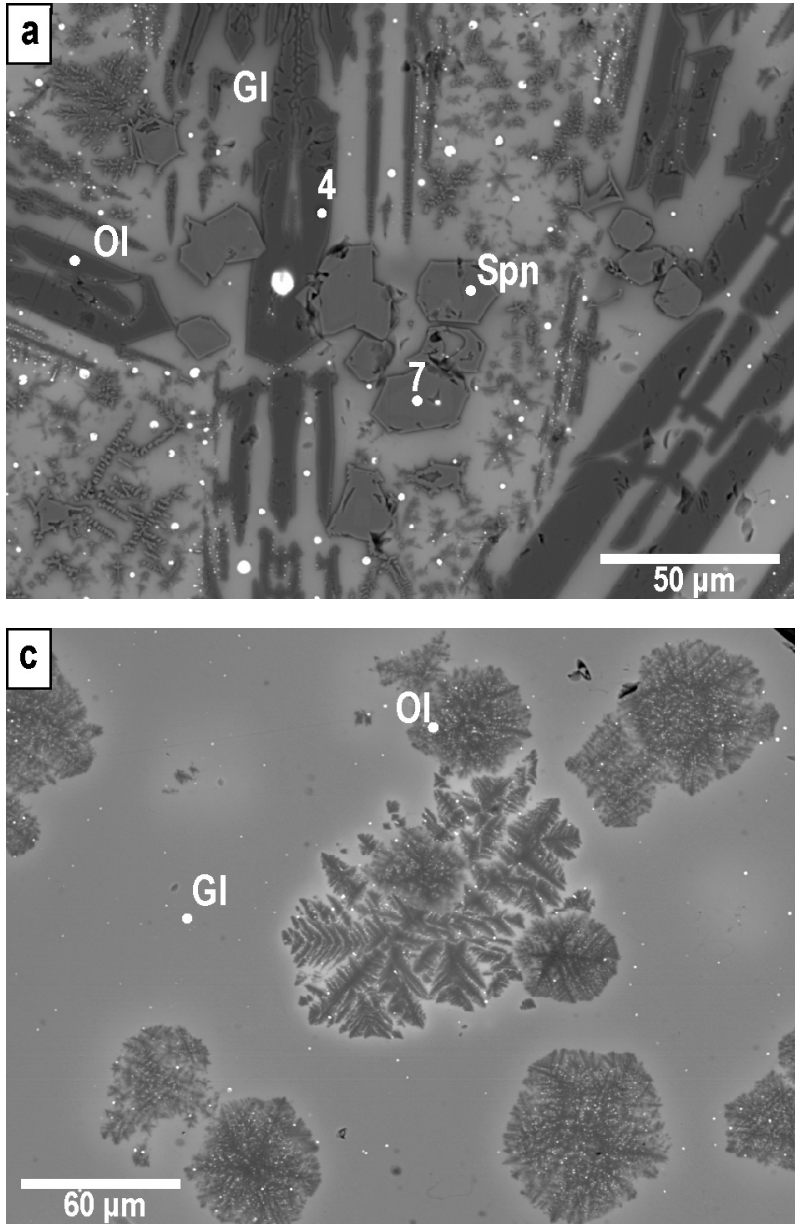

vyvinuta výrazná oscilační zonálnost, která je způsobena variací obsahů $\mathrm{Ba}$ a $\mathrm{K}$.

Olivíny mají v asociaci F2 podobu několik desetin mm dlouhých sloupcovitých skeletálních krystalů, uložených ve skle. $\mathrm{V}$ asociaci $\mathrm{F} 3$ jsou olivíny převážně izometrické s hypautomorfním omezením a velikostí nepřesahující desítky $\mu \mathrm{m}$. Zajímavý vývin mají olivíny ve vzorku CT3, kde tvoří dendritické krystaly uložené ve skle (obr. 2c). Svým složením olivín odpovídá fayalitu $(61,0-64,6 \mathrm{hm} . \% \mathrm{FeO}=89-90 \mathrm{~mol}$ \% Fa), jen s nepatrnou príměsí $\mathrm{Mn}(3,7-4,8 \mathrm{hm} . \% \mathrm{MnO}=5-7 \mathrm{~mol} . \% \mathrm{Te})$ a $\mathrm{Mg}$ $(1,5-1,8 \mathrm{hm} . \% \mathrm{MgO}=4-5 \mathrm{~mol} . \%$ Fo $)$.

Pyroxeny byly identifikovány pouze ve vzorku CT4, kde se nacházejí hojně ve formě krátce sloupcovitých krystalů hypautomorfního až xenomorfního omezení (velikost první desítky $\mu \mathrm{m}$ ). Často narůstají po obvodu větších krystalů živců. EDX analýzy ukázaly, že jde o Ca-Fe pyroxeny $\left(\mathrm{Fs}_{52} \mathrm{Wo}_{38} \mathrm{En}_{11}-\mathrm{Fs}_{51} \mathrm{Wo}_{37} \mathrm{En}_{13}\right)$ s príměsí $\mathrm{Mn}$ (2,5-2,2 hm. \% MnO).

\section{Diskuze a závěr}

Obsahy $\mathrm{CaO}$ jsou ve struskách obecně velmi nízké, jedinou výjimku tvoří vzorek CT4 (6,03 hm. \% CaO). Nízké obsahy $\mathrm{CaO}$ jsou nesystematicky provázené i nízkými obsahy $\mathrm{MgO}$ a $\mathrm{MnO}$. To poukazuje na absenci tavidel na bázi $\mathrm{CaO}$ a dobré vytř́ídění rudy. Navíc těžené mineralizace pelhřimovského rudního revíru jsou na karbonáty obecně chudé (Litochleb 2001). To potvrzují i nálezy úlomků zrudnění, tvořeného křemenem s vtroušeným

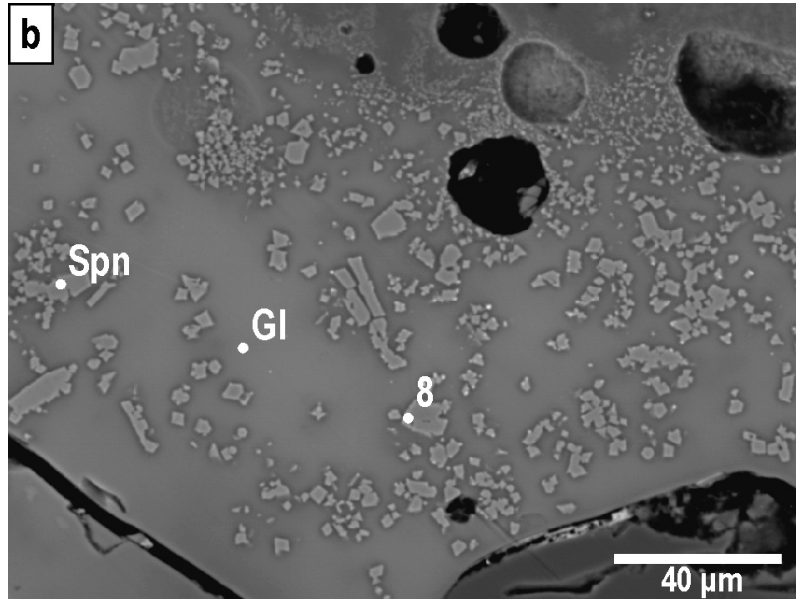

Obr. 2: Fázové složení a stavba strusek na snímcích ve zpětně rozptýlených elektronech: a - izometrická zrna spinelidů (Spn), skeletální krystaly olivínu $(\mathrm{Ol})$ a sklo $(\mathrm{Gl})$, bílé tečky jsou inkluze sulfidů nebo oxidů olova (vzorek CT2); b - krystaly spinelidů (Spn) ve skle (Gl) (vzorek CT3); c - dendritické krystaly olivínu (Ol) ve skle (Gl) (vzorek CT3). Číslované body na snímcích odpovídají číslům analýz v tabulce 2 .

Fig. 2: Phase composition and texture of the slags on the BSE images: a - isometric grains of spinelide (Spn), skeletal crystals of olivine (Ol) and glass (Gl) (sample CT2), white dots represent sulfidic inclusions or lead monoxide droplets; $b$ - spinelide crystals (Spn) embedded in glass (Gl) (sample CT3); c - dendritic olivine crystals (Ol) in glass (Gl) (sample CT3). Numbered points in pictures correspond to numbers of analyses in table 2.

pyritem, arzenopyritem, sfaleritem a galenitem zachycené na stařinách mezi nedalekým Černovem a Chrástkovem (Hrubý et al. 2012).

Zajímavý je zvýšený obsah Ba (9,2hm. \% Ba) ve vzorku CT4 provázený nejnižším obsahem $\mathrm{Pb}$ (1 940 ppm). Zvýšené obsahy Ba nejsou u tohoto typu materiálu zcela neobvyklé, jak je patrné z práce Kapusty et al. (2013), zaměřené na strusky jihlavského rudního revíru, kde je ve skle strusek přítomno až $23,32 \mathrm{hm}$. \% BaO. Podobně i Ströbele et al. (2010) uvádějí ze struskových hmot $\mathrm{z}$ německého Wieslochu až 10,05 hm. \% BaO. Zvýšené obsahy Ba naznačují možnost záměrného přidávání barytu do vsázky redukční tavby, zmíněnou i v práci Nováčka (2001). To by vzhledem $\mathrm{k}$ absenci barytu $\mathrm{v}$ těžených mineralizacích pelhřimovského rudního revíru (Litochleb 2001) znamenalo jeho import ze sousedních rudních revírů, např̀ jihlavského (Pluskal - Vosáhlo 1998). S vysokými obsahy Ba je spojena i přítomnost Ba-obohaceného živce.

Č́st As a Sb v průběhu pražení rudy odchází společně se S ve formě kouře (Vaněk - Velebil 2007). Obsahy $\mathrm{S}$ ve struskách jsou proto prŕmým ukazatelem kvality pražného procesu (Manasse - Mellini 2002). Strusky CT2 a CT3 mají nejnižší obsahy S $(0,11-0,28$ hm. \%), což svědčí o velmi kvalitním vypražení rudy, ale zároveň vykazují nejvyšší obsahy As a Sb. To může být způsobeno vyšším podílem minerálních fází jako je arzenopyrit, tetraedrit či pyrargyrit v rudním koncentrátu, případně nižší teplotou pražení. 
Tab. 2: Výsledky EDX analýz živců, olivínů, pyroxenů a spinelidů. Empirické vzorce olivínů jsou přepočteny na bázi 4 kyslíků, živec na 8 kyslíků a pyroxen na 6 kyslíků. Spinelidy byly přepočteny na 4 kyslíky a 3 kationty na vzorcovou jednotku, b. d. - pod mezí detekce.

Tab. 2: Representative EDX analyses of feldspar, olivine, pyroxene and spinelides (wt. \%). The empirical formulae of feldspar, olivine and pyroxene are recalculated on basis of 8, 4, and 6 atoms of oxygen, respectively. Spinelides were recalculated on basis of 4 oxygens and 3 cations per formula unit, b. d. - below detection limit.

\begin{tabular}{|l|c|c|c|c|c|c|c|c|}
\hline Vzorek & CT4 & CT4 & CT4 & CT2 & CT4 & CT4 & CT2 & CT3 \\
\hline Fáze & živec & živec & olivín & olivín & pyroxen & pyroxen & spinelid & spinelid \\
\hline $\mathrm{Bod}$ & bod1 & bod2 & bod3 & bod4 & bod5 & bod6 & bod7 & bod8 \\
\hline $\mathrm{SiO}_{2}$ & 47,6 & 49,6 & 30,9 & 29,6 & 50,2 & 50,2 & - & - \\
\hline $\mathrm{Al}_{2} \mathrm{O}_{3}$ & 22,4 & 21,5 & - & - & - & - & 3,5 & 59,2 \\
\hline $\mathrm{BaO}$ & 22,8 & 19,6 & - & - & - & - & - & - \\
\hline $\mathrm{CaO}$ & b. d. & b. d. & 0,9 & b. d. & 17,0 & 16,4 & - & - \\
\hline $\mathrm{FeO}^{\text {tot }}$ & b. d. & b. d. & 61,0 & 64,6 & 27,0 & 26,6 & 89,8 & 29,0 \\
\hline $\mathrm{MgO}^{-}$ & - & - & 1,5 & 1,8 & 3,5 & 4,2 & 0,9 & 11,1 \\
\hline $\mathrm{MnO}$ & - & - & 4,8 & 3,7 & 2,5 & 2,2 & 0,9 & b. d. \\
\hline $\mathrm{ZnO}^{-}$ & - & - & 0,6 & b. d. & b. d. & b. d. & b. d. & b. d. \\
\hline $\mathrm{K}_{2} \mathrm{O}$ & 6,5 & 7,6 & - & - & - & - & - & - \\
\hline $\mathrm{Na}_{2} \mathrm{O}$ & 0,9 & 1,1 & - & - & - & - & - & - \\
\hline $\mathrm{Suma}$ & 100,2 & 99,3 & 99,7 & 99,8 & 100,3 & 99,6 & 95,1 & 99,4 \\
\hline $\mathrm{Si}$ & 2,56 & 2,63 & 1,02 & 0,99 & 2,03 & 2,03 & & \\
\hline $\mathrm{Al}^{2}$ & 1,42 & 1,34 & & & & & 0,15 & 1,89 \\
\hline $\mathrm{Fe}^{3+}$ & & & & & & & 1,85 & 0,11 \\
\hline $\mathrm{Ba}$ & 0,48 & 0,41 & & & & & & \\
\hline $\mathrm{Ca}$ & & & 0,03 & 0,00 & 0,74 & 0,71 & & \\
\hline $\mathrm{Fe}{ }^{2+}$ & & & 1,69 & 1,82 & 0,91 & 0,90 & 0,93 & 0,55 \\
\hline $\mathrm{Mg}$ & & & 0,07 & 0,09 & 0,21 & 0,25 & 0,05 & 0,45 \\
\hline $\mathrm{Mn}$ & & & 0,14 & 0,10 & 0,09 & 0,08 & 0,03 & \\
\hline $\mathrm{Zn}$ & & & 0,02 & & & & & \\
\hline $\mathrm{K}$ & 0,45 & 0,51 & & & & & & \\
\hline $\mathrm{Na}$ & 0,09 & 0,11 & & & & & & \\
\hline $\mathrm{Catsum}$ & 5,00 & 5,00 & 2,97 & 3,01 & 3,98 & 3,97 & 3,00 & 3,00 \\
\hline
\end{tabular}




\section{Literatura}

Bernard, J. H. (1991): Empirical types of ore mineralizations in the Bohemian Massif. - Ústřední ústav geologický. Praha.

Ettler, V. - Legendre, O. - Bodénan, F. - Touray, J. C. (2001): Primary phases and natural weathering of old lead-zinc pyrometallurgical slag from Př́bram, Czech Republic. - Canadian Mineralogist, 39, 873-88.

Ettler, V. - Johan, Z. (2003): Mineralogy of metaloid phases in sulphide mattes from primary lead smelting. - Comptes Rendus Geoscience, 335, 1005-1012.

Ettler, V. - Červinka, R. - Johan, Z. (2009): Mineralogy of medieval slags from lead and silver smelting (Bohutín, Příbram district, Czech Republic): Towards estimation of historical smelting conditions. - Archaeometry, 51, 6, 987-1007.

Hrubý, P. - Hejhal, P. - Hoch, A. - Kočár, P. - Malý, K. - Machaňová, L. - Libor, P. - Štelcl, J. (2012): Středověký úpravnický a hornický areál Cvilínek u Černova na Pelhřimovsku. - Památky archeologické, 103, 339-418. Praha.

Kapusta, J. - Dolníček, Z - Malý, K. (2013): Středověké baryem bohaté strusky po tavbě polymetalických rud na vybraných lokalitách v Jihlavě. - Geologické výzkumy na Moravě a ve Slezsku, 20, 188-192.

Litochleb, J. (1981): K těžbě zlata v okolí Humpolce. - Rozpravy Národního technického Muzea v Praze, 76, Studie z dějin hornictví 11, 105-107.

Litochleb, J. (1996): Pelhřimovský rudní revír. - In: Sborník příspěvků ze semináře. K dějinám hornictví a důlních prací na Vysočině, Stř́ibrná Jihlava 1995, 8-18.

Litochleb, J. (2001): Pelhřimovský stř́brnonosný revír. - Bulletin mineralogicko-petrologického oddělení Národního muzea v Praze 9, 102-121.

Litochleb, J. - Pavlíček, V. (1981): Mineralogická charakteristika polymetalického zrudnění z Výskytné u Pelhřimova. - Sborník Jihočeského muzea v Českých Budějovicích, Př́rodní vědy, 21, 65-72.

Manasse, A. - Mellini, M. (2002): Chemical and textural characterization of medieval slags from the Massa Marittima smelting sites (Tuscany, Italy). - Journal of Cultural Heritage, 3, 187-98.

Pluskal, O. - Vosáhlo, J. (1998): Jihlavský rudní obvod. - Vlastivědný sborník Vysočiny, 13, 157-191.

Nováček, K. (2001): Nerostné suroviny středověkých Čech jako archeologický problém: bilance a perspektivy výzkumu se zaměřením na výrobu a zpracování kovů. - Archeologické rozhledy, 53, 2, 279-309.

Ströbele, F. - Wenzel, T. - Kronz, A. (2010): Mineralogical and geochemical characterization of high-medieval lead-silver smelting slags from Wiesloch near Heidelberg (Germany) - an approach to process reconstruction. - Archaeological and Anthropological Sciences, 2, 191-215.

Vaněk, V. - Velebil, D. (2007): Staré hutnictví stříbra. - Stř́ibrná Jihlava 2007, 188-205. 